\title{
A direct approach to the evaluation of structural shakedown limit considering limited kinematic hardening and non-isothermal effect
}

\author{
Zhiyuan $\mathrm{Ma}^{1}$, Haofeng Chen ${ }^{1,2 *}$, Yinghua Liu ${ }^{3}$, Fu-Zhen Xuan ${ }^{2}$ \\ ${ }^{1}$ Department of Mechanical \& Aerospace Engineering, University of Strathclyde, James Weir Building, 75 Montrose \\ Street, Glasgow G1 1 XJ, UK \\ ${ }^{2}$ Key Laboratory of Pressure Systems and Safety, Ministry of Education, East China University of Science and \\ Technology, Shanghai 200237, P.R. China \\ ${ }^{3}$ Department of Engineering Mechanics, Tsinghua University, Beijing 100084, People's Republic of China \\ "Corresponding author: haofeng.chen@strath.ac.uk
}

\begin{abstract}
This paper presents a novel direct method for the structural shakedown analysis considering limited kinematic hardening and non-isothermal effect. The Melan's static shakedown theorem is extended to consider limited kinematic hardening material and implemented into the Linear Matching Method (LMM) shakedown module. Instead of using a specific kinematic hardening rule and an explicit back stress field, the general nonlinear hardening laws are considered by using a two-surface hardening model. A two-stage procedure is developed in the extended LMM algorithm, which can generate the limited hardening shakedown envelope and the unlimited hardening curve efficiently and accurately. Also, the material non-isothermal effect is considered during the computation process of the shakedown limit by proposing a temperature-dependent hardening factor, in place of a constant and fictitious one. To validate the extended LMM method, a numerical test on a thin cylinder pipe with temperature-independent material properties is performed, and the results match well with ones from literature. Then, a numerical study on a typical aero-engine turbine disk is conducted to investigate the influence of temperature-dependent material properties and operating conditions. Several shakedown curves considering kinematic hardening effect are derived and adequately discussed. As a result, the extended LMM shakedown module is proven to be a robust, efficient and versatile tool for practical industrial problems.
\end{abstract}

Keywords: Direct method; Shakedown analysis; Limited kinematic hardening; Temperature dependence; Linear matching method.

\section{Introduction}

In the field of mechanical and aerospace engineering, it is essential to conduct structural integrity assessment and evaluate the load-bearing capacity of structures subjected to cyclic thermomechanical loads. Although the elastic limit of structures can be calculated to determine the design loads, it is usually considered to be over-conservative among industries. With a bounded total plastic dissipation in the structure, the shakedown limit is often adopted as an indicator of load-bearing capacity by allowing a small amount of plastic strain (Pham, 2007). In the case of cyclic loading conditions, the body will shake down when limited plastic strain is observed in the first few cycles, and pure elastic behaviour is found afterwards (Haofeng Chen, 2010). To determine the shakedown limit, a shakedown loading factor is calculated which scales the external loads until structural shakedown behaviour is reached while preventing the structural failure due to incremental collapse and alternating plasticity (Polizzotto, 1993).

For the evaluation of the shakedown loading factor, the finite element (FE) technique is widely used among researchers and engineers. Industrial design codes such as ASME Boiler \& Pressure Vessel Code (BPVC) (Boiler \& Code, 2007) and R5 procedure (Ainsworth, 2003) suggest conducting 
a step-by-step analysis using realistic material properties and detailed loading histories to determine the shakedown status of structures. However, the step-by-step analysis is generally time-consuming and requires a complete loading spectrum. Thus it can be highly challenging for the step-by-step analysis to determine the shakedown boundary of a specific structure when various loading combinations are considered. In this scenario, a number of direct methods have been proposed which can compute the shakedown boundary quickly by making a few hypotheses, including the generalized local stress strain (GLOSS) r-node method (Seshadri, 1995), the interior-point algorithm (Simon, 2013), the elastic compensation method (ECM) (Mackenzie, Boyle, \& Hamilton, 2000), and the linear matching method (LMM) (Haofeng Chen, 2010; HF Chen \& Ponter, 2001). As one of the direct approaches that modifies the elastic modulus, the LMM considers elastic-perfectly plastic (EPP) material and only requires the extreme vertices of the loading history for a path-independent shakedown assessment. Furthermore, the LMM framework has been integrated with Direct Steady Cycle Assessment (DSCA) (Lytwyn, Chen, \& Ponter, 2015) algorithm and implemented into commercial finite element software ABAQUS as a plug-in.

The original LMM algorithm considers Koiter's kinematic theorem (Koiter, 1960) to produce the upper bound shakedown limit, along with Melan's static theorem (Melan, 1938) for the lower bound shakedown limit computation. Based on the small deformation assumption, the original LMM only considers EPP material and ignores creep effect. However, the shakedown boundary calculated with EPP material could be over-conservative due to the presence of material hardening. Components subjected to cyclic loads would usually experience kinematic hardening, which is observed experimentally by the Bauschinger effect (Svensson, 1966). To describe the material response with kinematic hardening, various material constitutive models have been proposed (Armstrong \& Frederick, 1966; Prager, 1955; Ziegler, 1959). Nevertheless, these models can hardly be implemented into any direct methods because of the inherent demand for detailed loading spectrum and the evolution of an explicit back stress field. To address this problem, a two-surface model has been introduced by (Weichert \& Gross-Weege, 1988) to describe limited kinematic hardening using two bounding surfaces, i.e. the initial yield surface and the ultimate bounding surface. By combining the two-surface model with Melan's static theorem (Melan, 1938), many researchers (Bouby, de Saxcé, \& Tritsch, 2009; S. Chen, Liu, Li, \& Cen, 2011; Heitzer, Pop, \& Staat, 2000; Huang, Wan, Jiao, \& Chen, 2018; Pham, 2007; Pycko \& Maier, 1995; Ri \& Hong, 2018; Simon, 2013; Stein, Zhang, \& Huang, 1993; Weichert \& Gross-Weege, 1988) have addressed the effect of kinematic hardening on the shakedown boundary of structure. It has been widely acknowledged that for unlimited kinematic hardening where the translation of yield surface is not bounded, only the alternating plasticity mechanism is covered (König, 2012; A. Ponter, 1975). Still, some researchers believe that the back stress is bounded by specific hardening laws and solely consider the limited linear kinematic hardening in their work (Heitzer et al., 2000; Huang et al., 2018). While some other researchers consider limited nonlinear kinematic hardening where the back stress is bounded implicitly by the ultimate strength surface, such as in (Pham, 2007). In this paper, the formulations of general limited nonlinear kinematic hardening are adopted and implemented into the LMM algorithm, in which a sequence of linear equations are solved while the EPP shakedown limit, the unlimited hardening shakedown limit, and the limited kinematic hardening shakedown limit are computed simultaneously.

Although the research on kinematic hardening in shakedown analysis has been broadly conducted, there are still some limitations in existing literature that can be further investigated. Several researchers (Hachemi, 2005; Heitzer et al., 2000; Mouhtamid \& Weichert, 2008; Simon, 2013) have considered thermal loads induced by the temperature difference, but the non-isothermal effect on material properties have not been covered. For components operating in a high-temperature environment, especially in the aerospace industry, the material performance can be significantly weakened, and correspondingly, the structural shakedown boundary will shrink massively. Therefore, an innovative direct method considering temperature-dependent material properties is desperately needed for practical industrial use. Being robust and user-friendly, the extended LMM shakedown module has been developed which accept the input of both temperature-dependent yield stress and ultimate strength for shakedown analysis considering limited kinematic hardening. Furthermore, by 
virtue of a fully developed LMM framework, even a structural ratchetting boundary considering kinematic hardening can be achieved with some modifications in the LMM ratchet module (Haofeng Chen \& Ponter, 2010; Lytwyn et al., 2015).

In this work, the newly developed extended LMM algorithm is illustrated thoroughly, and some industrial cases are investigated using the proposed method. In Section 2, the numerical procedure of extending the Melan's static shakedown theorem for kinematic hardening material is clarified. In Section 3, the discretization and iteration process of the extended LMM method is given, as well as a flowchart for a clear clarification. In Section 4, some numerical examples are presented to justify the reliability and versatility of the extended LMM method. In Section 5, the work is summarised by drawing several conclusions.

\section{Numerical procedures}

Considering a body of an isotropic, elastic-perfectly plastic (EPP) material with the satisfaction of von Mises yield condition. A two-surface hardening model is adopted in this case to describe the behaviour of limited kinematic hardening with an initial yield stress $\sigma_{Y}$ and an ultimate strength $\sigma_{U}$. Having a volume $V$ and a surface $S$, the body is subjected to a cyclic temperature $\lambda \theta\left(x_{i}, t\right)$ within $V$ and surface loads $\lambda P_{i}\left(x_{i}, t\right)$ on the structure's surface $S_{T} \subseteq S$, as well as a prescribed displacement $u_{i}=0$ on the remainder surface $S_{u}$ where $S=S_{T} \cap S_{u}$ and $S_{T} \cup S_{u}=\emptyset$. The cyclic load history is considered over time cycle $0 \leq t \leq \Delta t$ and $\lambda$ indicates the load multiplier, which scales the loads within the loading domain.

\subsection{Melan's static shakedown theorem}

Melan's static shakedown theorem (Melan, 1938) has been widely used to calculate a lower bound shakedown factor. A linear-elastic analysis is firstly required accounting for all loading histories:

$$
\lambda \hat{\sigma}_{i j}=\lambda \hat{\sigma}_{i j}^{\theta}+\lambda \hat{\sigma}_{i j}^{P}
$$

where $\hat{\sigma}_{i j}^{\theta}$ and $\hat{\sigma}_{i j}^{P}$ denote the linear-elastic solutions with $\theta\left(x_{i}, t\right)$ and $P_{i}\left(x_{i}, t\right)$, respectively.

Then, for cyclic problems, a residual stress field is introduced in the cyclic load history during the time cycle $0 \leq t \leq \Delta t$ :

$$
\sigma_{i j}\left(x_{i}, t\right)=\lambda \hat{\sigma}_{i j}\left(x_{i}, t\right)+\bar{\rho}_{i j}\left(x_{i}\right)+\rho_{i j}^{r}\left(x_{i}, t\right)
$$

where $\bar{\rho}_{i j}\left(x_{i}\right)$ is the constant part of the residual stress field, which is time-independent and selfequilibrium. $\rho_{i j}^{r}\left(x_{i}, t\right)$ is the varying part of the residual stress field. In the case of shakedown, $\rho_{i j}^{r}\left(x_{i}, t\right)=0$. Thus, Melan's static shakedown theory can be stated as follows:

The structure will shake down, if a time-independent residual stress field $\bar{\rho}_{i j}\left(x_{i}\right)$ can be found so that the sum of $\bar{\rho}_{i j}\left(x_{i}\right)$ and the scaled elastic stress filed $\lambda \hat{\sigma}_{i j}\left(x_{i}, t\right)$ satisfy the yield condition for arbitrary loading path in a given loading domain at any structural location $x$ and time point $t:$

$$
f_{Y}\left[\lambda \hat{\sigma}_{i j}\left(x_{i}, t\right)+\bar{\rho}_{i j}\left(x_{i}\right), \sigma_{Y}\left(x_{i}\right)\right] \leq 0, \forall x \in V, \forall t
$$

\subsection{Extended static shakedown theorem considering limited kinematic hardening}

The concept of the two-surface model is proposed by (Weichert \& Gross-Weege, 1988) to consider limited kinematic hardening behaviour. The size of both the yield surface and the bounding surface are fixed, while the yield surface can translate within the bounding surface, as shown in Fig. 1. The time-independent back stress $A_{i j}\left(x_{i}\right)$ represents the translation of the centre of yield surface and $\sigma_{i j}^{\prime c}$ is the stress at yield, where $\sigma_{i j}^{\prime c}\left(x_{i}, t\right)=\lambda \hat{\sigma}_{i j}\left(x_{i}, t\right)+\bar{\rho}_{i j}\left(x_{i}\right)$. The reduced stress $v_{i j}^{\prime}\left(x_{i}, t\right)=$ $\sigma_{i j}^{\prime c}\left(x_{i}, t\right)-A_{i j}\left(x_{i}\right)$ is bounded by the initial yield surface:

$$
f_{Y}\left[\sigma_{i j}^{\prime c}\left(x_{i}, t\right)-A_{i j}\left(x_{i}\right), \sigma_{Y}\left(x_{i}\right)\right] \leq 0
$$

Meanwhile, the stress at yield $\sigma_{i j}^{\prime c}\left(x_{i}, t\right)$ is bounded by the ultimate strength: 


$$
f_{U}\left[\sigma_{i j}^{\prime c}\left(x_{i}, t\right), \sigma_{U}\left(x_{i}\right)\right] \leq 0
$$

By substituting $\sigma_{i j}^{\prime c}\left(x_{i}, t\right)=\lambda \hat{\sigma}_{i j}\left(x_{i}, t\right)+\bar{\rho}_{i j}\left(x_{i}\right)$ into (4) and (5), the extended static shakedown theorem limit considering limited kinematic hardening is stated as follows:

The structure will shake down, if a time-independent residual stress field $\bar{\rho}_{i j}\left(x_{i}\right)$ and a timeindependent back stress field $A_{i j}\left(x_{i}\right)$ can be found so that both the yield condition $f_{Y} \leq 0$ and the bounding condition $f_{U} \leq 0$ are satisfied for arbitrary loading path in a given loading domain at any structural location $x$ and time point $t$ :

$$
\begin{gathered}
f_{Y}\left[\lambda \hat{\sigma}_{i j}\left(x_{i}, t\right)+\bar{\rho}_{i j}\left(x_{i}\right)-A_{i j}\left(x_{i}\right), \sigma_{Y}\left(x_{i}\right)\right] \leq 0 \\
f_{U}\left[\lambda \hat{\sigma}_{i j}\left(x_{i}, t\right)+\bar{\rho}_{i j}\left(x_{i}\right), \sigma_{U}\left(x_{i}\right)\right] \leq 0
\end{gathered}
$$

The theorem has been described in (Simon, 2013) and is not restricted by specific hardening laws. Thus it is known as unrestricted kinematic hardening limited by general nonlinear hardening laws. In this way, the path-independent shakedown theorem is simplified as much as possible without having an explicit back stress field, but only two hardening parameters: the initial yield stress and the ultimate strength. However, there are some assumptions and hypotheses (Pham, 2017) that should be noticed while adopting the theorem, including the positive hysteresis postulate, the maximal dissipation hypothesis, the strictly-stable hardening hypothesis, and the multiaxial Bauschinger hypothesis.

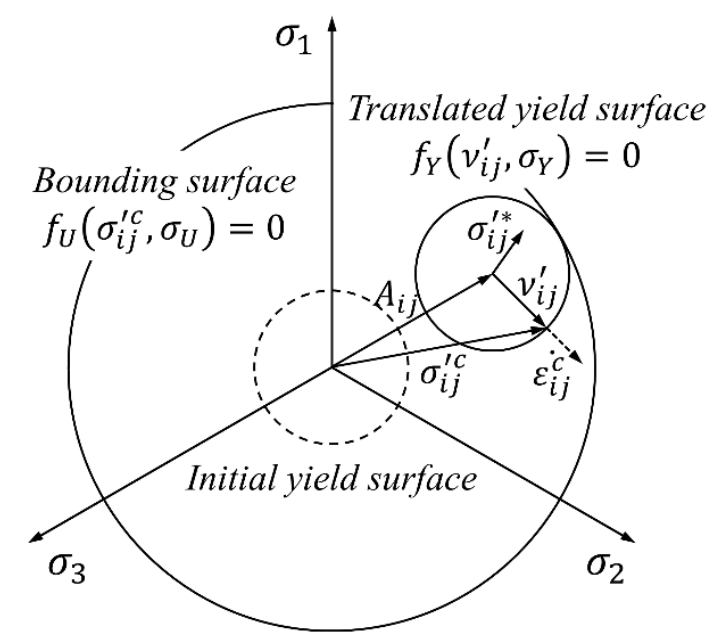

Fig. 1. A two-surface model for limited kinematic hardening behaviour in the deviatoric plane.

\subsection{Description of loading domain}

As stated in (Simon, 2013), the loading history $H\left(x_{i}, t\right)$ can be considered as the sum of unity loading $P_{0}\left(x_{i}\right)$ times the time-dependent load multipliers $\phi_{l}(t)$ :

$$
H\left(x_{i}, t\right)=\sum_{l=1}^{N} \phi_{l}(t) P_{0}\left(x_{i}\right)
$$

where $N$ denotes the number of loading sets, and $l$ denotes an individual loading case. Due to the path-independency of the proposed theorem, only the convex vertices of a loading domain are considered to simplify the loading history. Hence the load multipliers $\phi_{l}(t)$ are bounded by $\phi_{l}^{-}$and $\phi_{l}^{+}$which represents the boundary of a loading domain. The set of all bounded loading sets combination $U$ is then defined as follows:

$$
U=\left\{\phi_{l} \mid \phi_{l}^{-} \leq \phi_{l} \leq \phi_{l}^{+}, \forall l \in[1, N]\right\}
$$

Therefore, the loading domain $\Omega$ can be derived as follows:

$$
\Omega=\left\{H\left(x_{i}, t\right) \mid H\left(x_{i}, t\right)=\sum_{l=1}^{N} \mu_{l}(t) P_{0}\left(x_{i}\right), \forall \mu_{l} \in U\right\}
$$

Finally, the linear-elastic stress history $\hat{\sigma}_{i j}\left(x_{i}, t\right)$ becomes:

$$
\hat{\sigma}_{i j}\left(x_{i}, t\right)=\sum_{l=1}^{N} \phi_{l}(t) \hat{\sigma}_{i j}\left(x_{i}\right)
$$




\section{Extended Linear Matching Method for shakedown analysis}

\subsection{The effect of temperature-dependent material properties}

Some material properties are greatly affected by temperature, so using temperature-dependent material parameters makes the results more accurate and acceptable among industries. Thus the temperature dependency of both yield stress $\sigma_{Y}$ and ultimate strength $\sigma_{U}$ in the two-surface model is considered in order to solve industrial problems with cyclic high-temperature loading conditions. The temperature-dependent material properties are determined by the temperature $T$ at Gauss points for each vertex of the loading domain using interpolation and extrapolation techniques. During the iteration process, the temperature is scaled by the shakedown factor calculated from the last iteration, and hence the temperature-dependent yield stress $\sigma_{Y}(T)$ and the ultimate strength $\sigma_{U}(T)$ are updated correspondingly.

Few researchers have considered ultimate strength $\sigma_{U}$ from realistic material properties, but only defined it as scaled initial yield stress:

$$
\sigma_{U}=K \sigma_{Y}
$$

where $K$ is a fictitious hardening factor. In this paper, a temperature-dependent hardening factor $K(T)$ is proposed, which indicates a dynamic ratio of ultimate strength to yield stress based on local temperature:

$$
K(T)=\frac{\sigma_{U}(T)}{\sigma_{Y}(T)}
$$

Furthermore, for the conservative selection of material parameters, (Pham, 2008) suggests taking the "fatigue limit for arbitrary high-cycle loading" for the initial yield stress $\sigma_{Y}$, and the "high-cycle ratchetting" stress for the ultimate strength $\sigma_{U}$. However, due to the lack of experimental data for the material chosen here, the temperature-dependent $0.2 \%$ proof stress $\sigma_{s}(T)$ and the temperaturedependent ultimate tensile strength $\operatorname{UTS}(T)$ are chosen as $\sigma_{Y}(T)$ and $\sigma_{U}(T)$ respectively for the following numerical examples, such that:

$$
\operatorname{UTS}(T)=K(T) \sigma_{S}(T)
$$

\subsection{The LMM algorithm for limited kinematic hardening material}

The overall LMM algorithm for limited kinematic hardening material consists of two iterative stages. Stage 1 contains a series of newly developed formulae for the satisfaction of (6), while stage 2 utilises the original LMM algorithm for the satisfaction of (7). Two stages are operated simultaneously once the process starts. After the convergence condition is satisfied, the final shakedown multiplier is calculated based on the results of two stages. According to the maximum work principle, as shown in Fig. 1:

$$
\left(\sigma_{i j}^{\prime c}-A_{i j}\right) \dot{\varepsilon}_{i j}^{c} \geq\left(\sigma_{i j}^{\prime *}-A_{i j}\right) \dot{\varepsilon}_{i j}^{c}
$$

where $\sigma_{i j}^{\prime c}$ is the stress at yield associated with plastic strain rate $\dot{\varepsilon}_{i j}^{c}$ and $\sigma_{i j}^{\prime *}$ lies within yield surface. Suppose that $\sigma_{i j}^{\prime *}=\lambda \hat{\sigma}_{i j}^{\prime}+\bar{\rho}_{i j}$ where $\lambda$ is the shakedown limit and $\bar{\rho}_{i j}$ is the corresponding constant residual stress field. Assume that a compatible strain increment $\Delta \varepsilon_{i j}^{c}$ is composed of a series of incompressible and kinematically admissible strain rate history $\dot{\varepsilon}_{i j}^{c}$ :

$$
\int_{0}^{\Delta t} \dot{\varepsilon}_{i j}^{c} d t=\Delta \varepsilon_{i j}^{c}
$$

where $\Delta \varepsilon_{i j}^{c}$ is compatible with a displacement increment field $\Delta u_{i}^{c}$ :

$$
\Delta \varepsilon_{i j}^{c}=\frac{1}{2}\left(\frac{\partial \Delta u_{i}^{c}}{\partial x_{j}}+\frac{\partial \Delta u_{j}^{c}}{\partial x_{i}}\right)
$$

For stage 1, according to (6), the shakedown factor for unlimited kinematic hardening case $\lambda_{U H}$ is given by:

$$
\lambda_{U H}=\min \left\{\frac{\sigma_{Y}(T)}{\bar{\sigma}\left(\widehat{\sigma}_{i j}\left(t_{n}\right)+\bar{\rho}_{i j U H}-A_{i j}\right)}\right\}
$$

where $\bar{\sigma}$ is the effective von Mises stress. For stage 2, an upper bound shakedown factor $\lambda$ is derived from the kinematic shakedown theorem and flow rule: 


$$
\lambda=\frac{\int_{V} \int_{0}^{\Delta t} \sigma_{U}(T) \bar{\varepsilon}\left(\dot{\varepsilon}_{i j}^{c}\right) d t d V}{\int_{V} \int_{0}^{\Delta t} \widehat{\sigma}_{i j} \dot{\varepsilon}_{i j}^{c} d t d V}
$$

where $\overline{\dot{\varepsilon}}=\sqrt{(2 / 3) \dot{\varepsilon}_{i j} \dot{\varepsilon}_{i j}}$ is the effective strain rate. Hence the final shakedown factor $\lambda_{K H}$ considering limited kinematic hardening is given by:

$$
\lambda_{K H}=\min \left\{\lambda_{U H}, \lambda\right\}
$$

To solve the above problem, a typical programming technique from (A. R. Ponter \& Engelhardt, 2000 ) is used in which a sequence of linear equations is defined. In this process, the elastic modulus is modified at every integration points for each iteration so that the yield condition is matched, as shown in Fig. 2. Next, the iteration procedure for both stages will be described separately, but in the programming code, both stages are conducted together for better computational efficiency.

For stage 1, the iterative linear problem is:

$$
\dot{\varepsilon}_{i j U H}^{f^{\prime}}=\frac{1}{\mu_{U H}(t)}\left\{\lambda_{U H}^{i} \hat{\sigma}_{i j}(t)+\left(\bar{\rho}_{i j U H}-A_{i j}\right)^{f}\right\}^{\prime}
$$

where $\mu_{U H}(t)=\sigma_{Y}(T) / \overline{\dot{\varepsilon}}\left(\dot{\varepsilon}_{i j}^{i}\right)$ is the modified shear modulus. Superscripts $i$ and $f$ refer to the initial and final stage of a single iteration, respectively. Superscript ' denotes the deviator component of stress or strain. $\dot{\varepsilon}_{i j U H}^{f}$ is a kinematically admissible strain rate history and $\bar{\rho}_{i j U H}$ is a time-independent self-equilibrium residual stress field. $A_{i j}$ is the back stress. Integrating (21) over the time cycle produces a linear relationship between $\Delta \varepsilon_{i j U H}^{f^{\prime}}$ and $\bar{\rho}_{i j U H}^{f^{\prime}}$ :

$$
\Delta \varepsilon_{i j U H}^{f^{\prime}}=\left\{\int_{0}^{\Delta t} \frac{1}{\mu_{U H}} \lambda_{U H}^{i} \hat{\sigma}_{i j} d t\right\}+\left\{\int_{0}^{\Delta t} \frac{1}{\mu_{U H}} d t\right\}\left(\bar{\rho}_{i j U H}-A_{i j}\right)^{f^{\prime}}
$$

For the failure mode of reverse plasticity $\Delta \varepsilon_{i j U H}^{f \prime}=0$, and (22) can be solved directly for $\left(\bar{\rho}_{i j U H}-A_{i j}\right)^{f \prime}:$

$$
\left(\bar{\rho}_{i j U H}-A_{i j}\right)^{f^{\prime}}=-\frac{\int_{0}^{\Delta t} \frac{1}{\mu_{U H}} \lambda_{U H}^{i} \widehat{\sigma}_{i j} d t}{\int_{0}^{\Delta t} \frac{1}{\mu_{U H}} d t}
$$

Hence the expression for the history of $\dot{\varepsilon}_{i j U H}^{f^{\prime}}$ is given by substituting (23) into (21). $\lambda_{U H}$ is then calculated by (18).

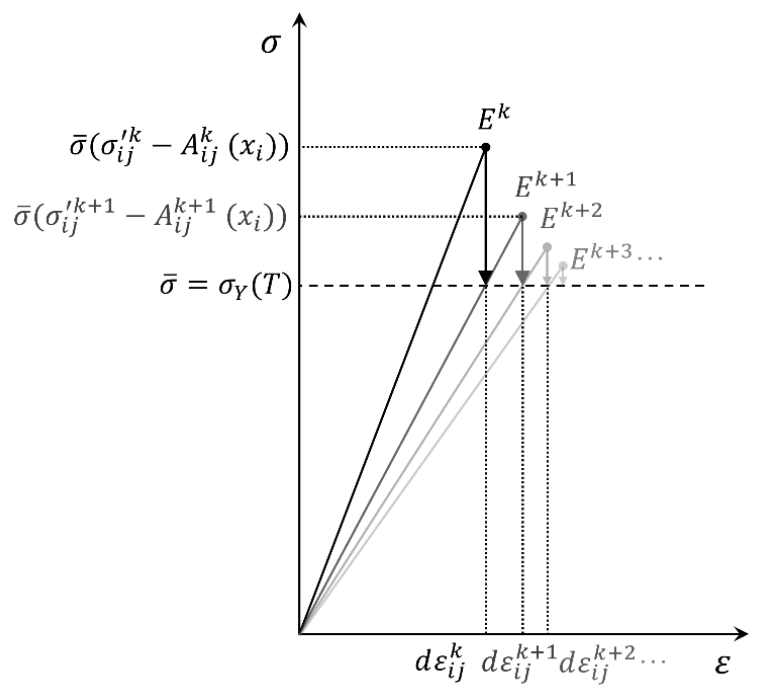

Fig. 2. The matching procedure of the LMM considering kinematic hardening behaviour.

For stage 2, the procedure has been described in detail in (HF Chen \& Ponter, 2001). The difference here is to use the $\sigma_{U}$ as the yield strength instead of $\sigma_{Y}$. The iterative linear problem is:

$$
\dot{\varepsilon}_{i j}^{f^{\prime}}=\frac{1}{\mu}\left(\lambda^{i} \hat{\sigma}_{i j}+\bar{\rho}_{i j}^{f}\right)^{\prime}
$$

where $\mu=\sigma_{U}(T) / \overline{\dot{\varepsilon}}$. Integrating (24) over the time cycle we have:

$$
\Delta \varepsilon_{i j}^{f^{\prime}}=\frac{1}{\bar{\mu}}\left(\bar{\rho}_{i j}^{f^{\prime}}+\sigma_{i j}^{i n^{\prime}}\right)
$$


where $\sigma_{i j}^{i n^{\prime}}=\bar{\mu}\left\{\int_{0}^{\Delta t} \frac{1}{\mu(t)} \lambda^{i} \hat{\sigma}_{i j}^{\prime}(t) d t\right\}$ and $\frac{1}{\bar{\mu}}=\int_{0}^{\Delta t} \frac{1}{\mu_{n}} d t$. Then a new upper bound $\lambda^{f}$ can be calculated by (19). It has been proved in (A. R. Ponter \& Engelhardt, 2000) that $\lambda$ decreases monotonically during iterations process, and it converges to a constant value intrinsically.

\subsection{Implementation of numerical procedures into ABAQUS}

The LMM algorithm for limited kinematic hardening material has been implemented into commercial finite element software ABAQUS using user subroutines UMAT and URDFIL. Considering the loading domain described in Section 2.3, the iteration steps are given as follows:

1) For the first iteration, iteration number $k=1$, an initialisation operation is conducted:

$$
\mu^{1}=\mu_{U H}^{1}=\frac{E}{2(1+v)}, \lambda^{1}=\lambda_{U H}^{1}=1
$$

where $\mu$ is the shear modulus, $E$ is the original Young's modulus, $v$ is the Poisson's ratio, $\lambda$ is the shakedown factor. Besides, the elastic history $\hat{\sigma}_{i j}\left(t_{n}\right)$ is calculated and saved into data files using linear elastic analysis with external loading conditions for each load instance. Temperature-dependent yield stress $\sigma_{Y}(T)$ and ultimate strength $\sigma_{U}(T)$ are also initialised to user-defined values.

2) For the $(k+1)^{\text {th }}$ iteration, stage 1 computation is performed first:

$$
\begin{gathered}
\lambda_{U H}^{k+1}=\lambda_{U H}^{k} \\
\mu_{n U H}^{k+1}=\frac{\sigma_{Y}(T)}{\bar{\varepsilon}\left(\Delta \varepsilon_{i j U H}^{n k}\right)}
\end{gathered}
$$

The expressions (21) to (23) become:

$$
\begin{gathered}
d \varepsilon_{i j U H}^{n(k+1)}=\frac{1}{\lambda_{U H}^{k+1}\left(t_{n}\right)}\left\{\lambda_{U H}^{k+1} \hat{\sigma}_{i j}\left(t_{n}\right)+\left(\bar{\rho}_{i j U H}-A_{i j}\right)^{k+1}\right\} \\
\left(\bar{\rho}_{i j U H}-A_{i j}\right)^{k+1}=-\frac{\sum_{n=1}^{r} \frac{1}{\mu_{n U H}^{k+1}} \lambda_{U H}^{k+1} \widehat{\sigma}_{i j}\left(t_{n}\right)}{\sum_{n=1}^{r} \frac{1}{\mu_{n U H}^{k+1}\left(t_{n}\right)}}
\end{gathered}
$$

For the same iteration number, the stage 2 calculation is then conducted:

$$
\begin{gathered}
\lambda^{k+1}=\lambda^{k} \\
\mu_{n}^{k+1}=\frac{\sigma_{U}(T)}{\bar{\varepsilon}\left(\Delta \varepsilon_{i j}^{n k}\right)} \\
\frac{1}{\bar{\mu}^{k+1}}=\sum_{n=1}^{r} \frac{1}{\mu_{n}^{k+1}} \\
\sigma_{i j}^{i n(k+1)}=\bar{\mu}^{k+1}\left(\sum_{n=1}^{r} \frac{\lambda^{k+1} \widehat{\sigma}_{i j}\left(t_{n}\right)}{\mu_{n}^{k+1}}\right)
\end{gathered}
$$

After that, a linear elastic Jacobian matrix $[J]^{k+1}$ is constructed based on the modified shear modulus $\bar{\mu}^{k+1}$ in (33). So the self-equilibrium time-independent residual stress field $\bar{\rho}_{i j}^{k+1}$ can be calculated:

$$
\bar{\rho}_{i j}^{k+1}=[J]^{k+1} \Delta \varepsilon_{i j}^{k+1}-\sigma_{i j}^{i n(k+1)}
$$

Then the strain rate for each load instance $\Delta \varepsilon_{i j}^{n(k+1)}$ is calculated using the compliance matrix $[C]_{n}^{k+1}$, which is derived from $\mu_{n}^{k+1}$ :

$$
\Delta \varepsilon_{i j}^{n(k+1)}=[C]_{n}^{k+1}\left(\bar{\rho}_{i j}^{k+1}+\hat{\sigma}_{i j}^{k+1}\left(t_{n}\right)\right)
$$

3) After the $(k+1)^{\text {th }}$ iteration is completed, the post-processing procedure will be performed before proceeding to the next iteration. Based on (18), the unlimited hardening shakedown factor $\lambda_{U H}^{k+1}$ can be calculated by:

$$
\lambda_{U H}^{k+1}=\min \left\{\frac{\sigma_{Y}(T)}{\bar{\sigma}\left(\widehat{\sigma}_{i j}\left(t_{n}\right)+\left(\bar{\rho}_{i j U H}-A_{i j}\right)^{k+1}\right)}\right\}
$$

The bounding shakedown factor $\lambda^{k+1}$ is also calculated by using the ABAQUS energy file for volume integration computation: 


$$
\lambda^{k+1}=\frac{\int_{V}\left(\sigma_{U}(T) \sum_{n=1}^{r} \bar{\varepsilon}_{n}^{k+1}\right) d V}{\int_{V}\left(\sum_{n=1}^{r} \dot{\varepsilon}_{i j}^{n(k+1)} \hat{\sigma}_{i j}\left(t_{n}\right)\right) d V}
$$

Finally, after convergence is reached for both stages, the shakedown factor $\lambda_{K H}$ considering limited kinematic hardening is given by (20). The whole calculation process has been further plotted in the form of a flowchart, as shown in Fig. 3. 


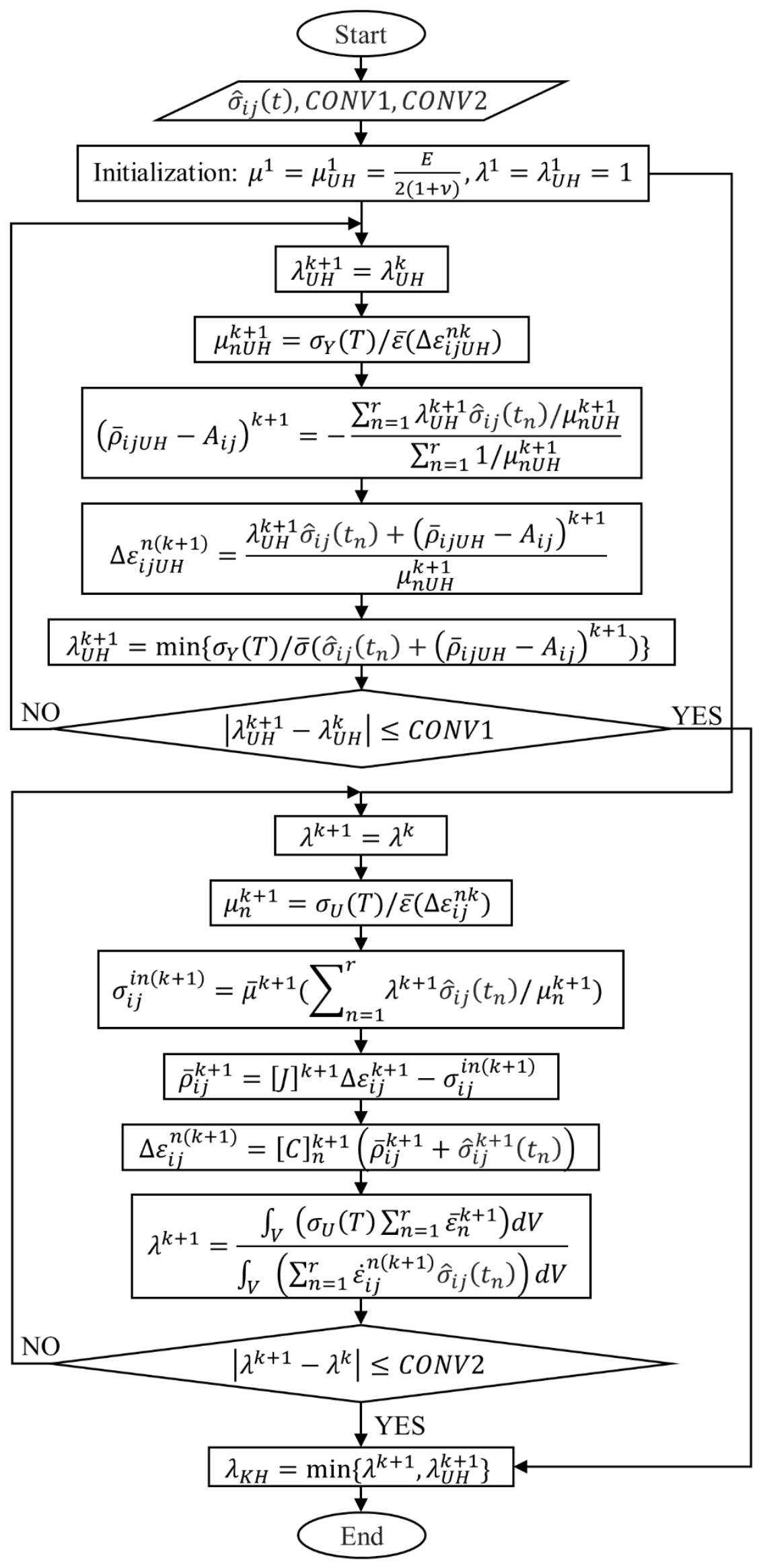

Fig. 3. Flowchart of the extended LMM algorithm for shakedown analysis with limited kinematic hardening material. 


\section{Numerical examples}

\subsection{A thin cylinder pipe}

The effect of kinematic hardening on shakedown boundaries of thin cylinder pipes has been studied by several researchers (Hachemi, 2005; Heitzer et al., 2000; Mouhtamid \& Weichert, 2008; Simon, 2013), so the same problem is considered here to compare and validate the numerical results from the LMM. As shown in Fig. 4(a), a thin pipe with the radius $R$ and the thickness $d=0.1 R$ has been simplified to a 2D axisymmetric problem, which is identical to the geometry used in (Heitzer et al., 2000). On the interior side of the thin pipe, the reference pressure $P=1 \mathrm{MPa}$ and the temperature boundary condition of $204.38{ }^{\circ} \mathrm{C}$ are applied. On the exterior side of the thin pipe, the temperature boundary condition of $0{ }^{\circ} \mathrm{C}$ is applied, which forms a temperature gradient $\Delta T$ in the thickness direction. Both mechanical and thermal loads are cyclic in this case. A steady-state thermal analysis has been conducted and the temperature field is given in Fig. 4(b). The FE model is meshed into 500 quadratic elements of type CAX8R. As shown in Fig. 4(c), the loading domain is made up of four load vertices: $V(1)=(P, 0) ; V(2)=(0, \Delta T) ; V(3)=(P, \Delta T) ; V(4)=(0,0)$. The corresponding loading condition is also demonstrated in Fig. 5, where four load instances can be found in each cycle.

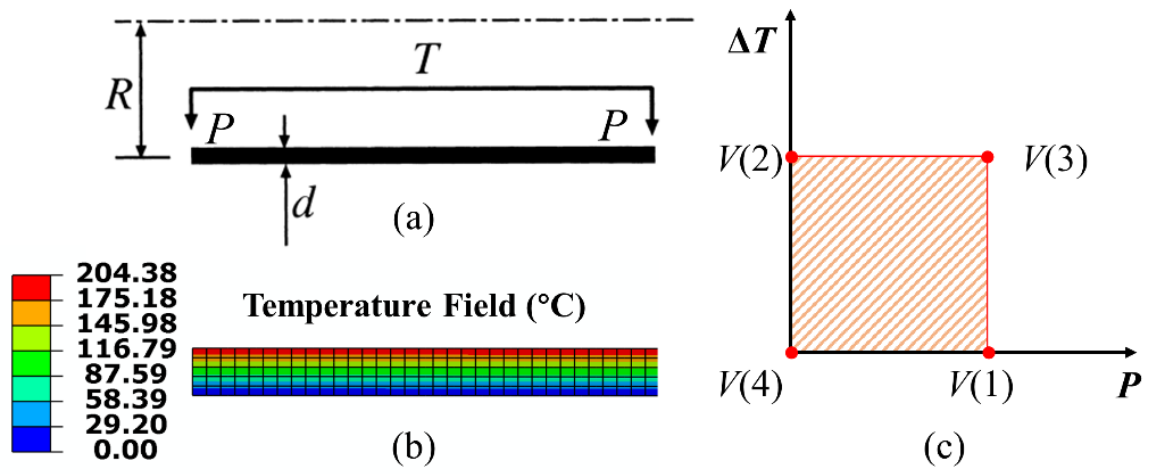

Fig. 4. A typical thin pipe: (a) geometry from (Heitzer et al., 2000); (b) mesh and temperature distribution; (c) loading domain.

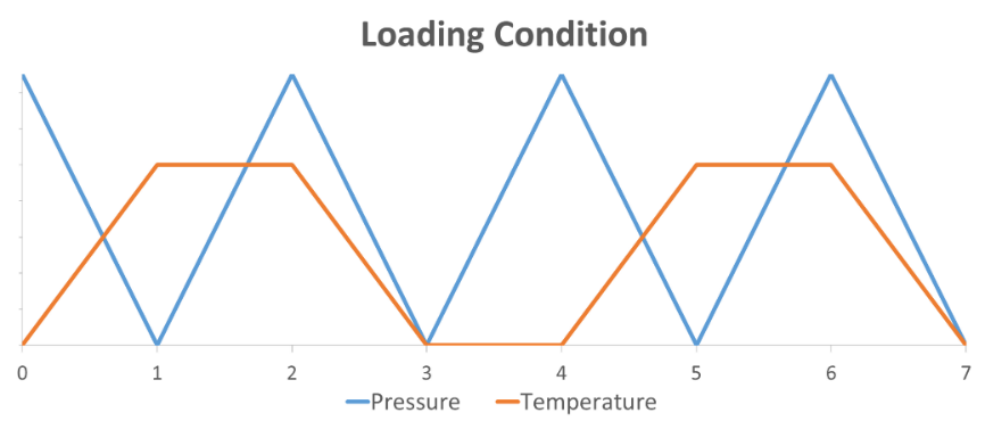

Fig. 5. Loading condition for the shakedown analysis.

A number of analyses have been done with various loading combinations to obtain the data points in Fig. 6. The shakedown limit analyses (solid lines) are conducted using the newly developed extended LMM for shakedown analysis considering limited kinematic hardening. While the ratchet limit analyses (dashed lines) are also conducted using the Direct Steady Cycle Analysis (DSCA) module in the LMM. Both the inner pressure $P$ and the temperature gradient $\Delta T$ are normalised by the limit load $P_{0}$ and the reverse plasticity limit $\Delta T_{0}$, respectively. In addition, a series of fictitious constant hardening factors $K$ are chosen in order to compare the results from the LMM with published ones from literature.

As presented in Fig. 6, the ratchet boundary is proportional to the hardening factor and approaches the $\mathrm{Y}$-axis gradually with increasing temperature level. The reason is that for ratchet limit, the main 
failure mechanism is incremental collapse, which is highly affected by the bounding ultimate strength $\sigma_{U}=K \sigma_{Y}, K \in\{1.2,1.35,1.5\}$. Apart from incremental collapse, the shakedown limit is also bounded by another criterion: alternating plasticity, which is represented by the unlimited hardening limit (König, 2012). The unlimited hardening is not influenced by the kinematic hardening factor, but only by the original yield stress $\sigma_{Y}$. Therefore, due to the increase of limit load, the lower part of the shakedown boundaries intersects with the $\mathrm{X}$-axis at $P / P_{0}=1,1.2,1.35,1.5$, respectively. Meanwhile, the upper part of the shakedown boundaries representing the alternating plasticity limit is strictly bounded by the unlimited hardening limit.

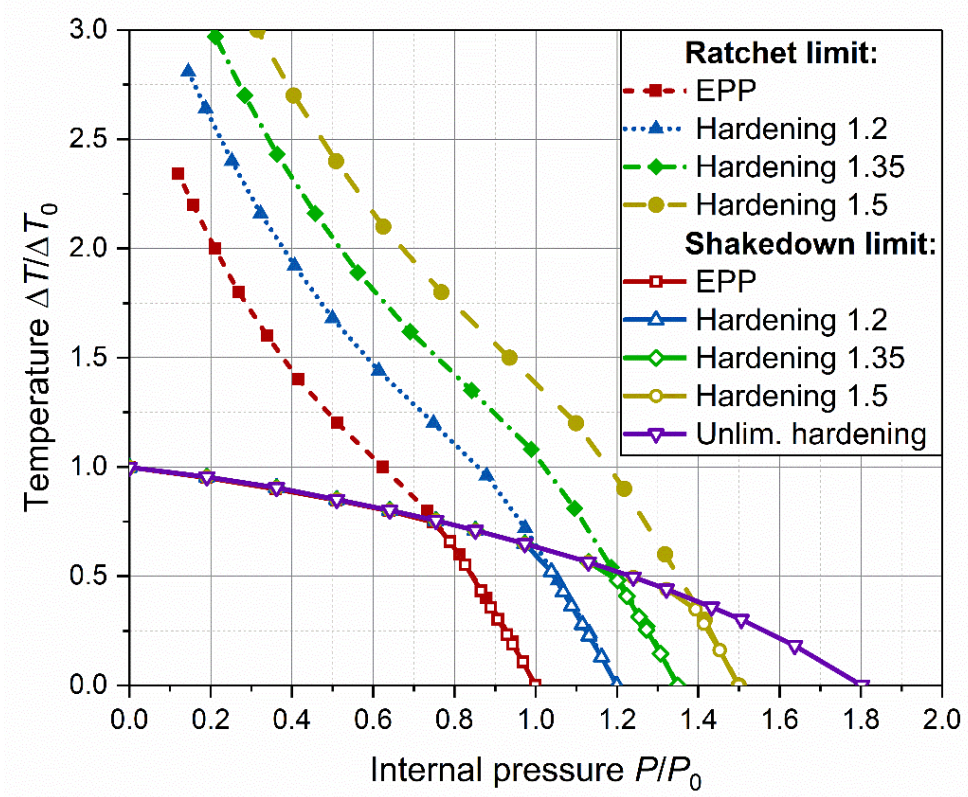

Fig. 6. Ratchet and shakedown limit of the thin pipe with various fictitious hardening factors.

To validate the results, a comparison between the LMM and literature is made and shown in Fig. 7 9. It can be observed in Fig. 7 that for shakedown boundaries with limited kinematic hardening effect, the LMM results agree well with results from (Heitzer et al., 2000) using the modified basis reduction method. As presented in Fig. 8, the LMM results also match the ones from (Simon, 2013) using the interior-point algorithm. Nevertheless, some differences can still be found in the transition region between two failure mechanisms, which are caused by mesh strategy and numerical deviations. Furthermore, in Fig. 9, the shakedown multipliers $\lambda$ from the LMM are compared with the ones selected from literature (Heitzer et al., 2000; Mouhtamid \& Weichert, 2008; Simon, 2013) in radial directions starting from the origin point. It can be seen that all data points can be placed within the region with a factor of 0.07 , which proves the accuracy and reliability of the extended LMM algorithm for shakedown analysis with limited kinematic hardening material. 


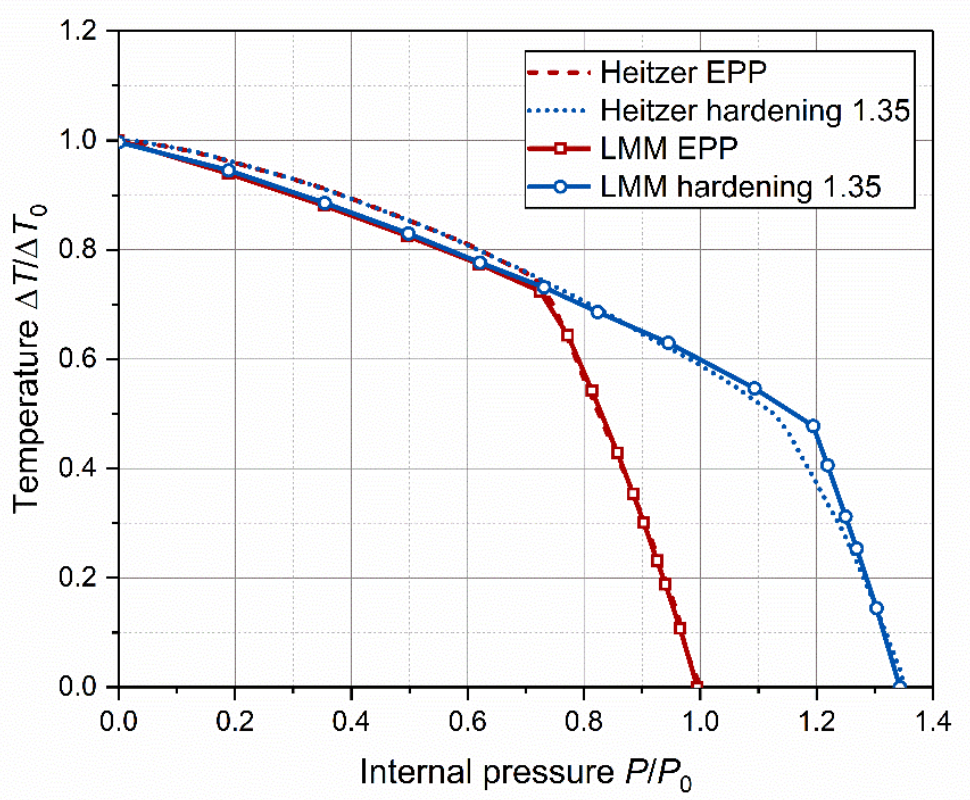

Fig. 7. Comparison of shakedown boundaries with results from (Heitzer et al., 2000).

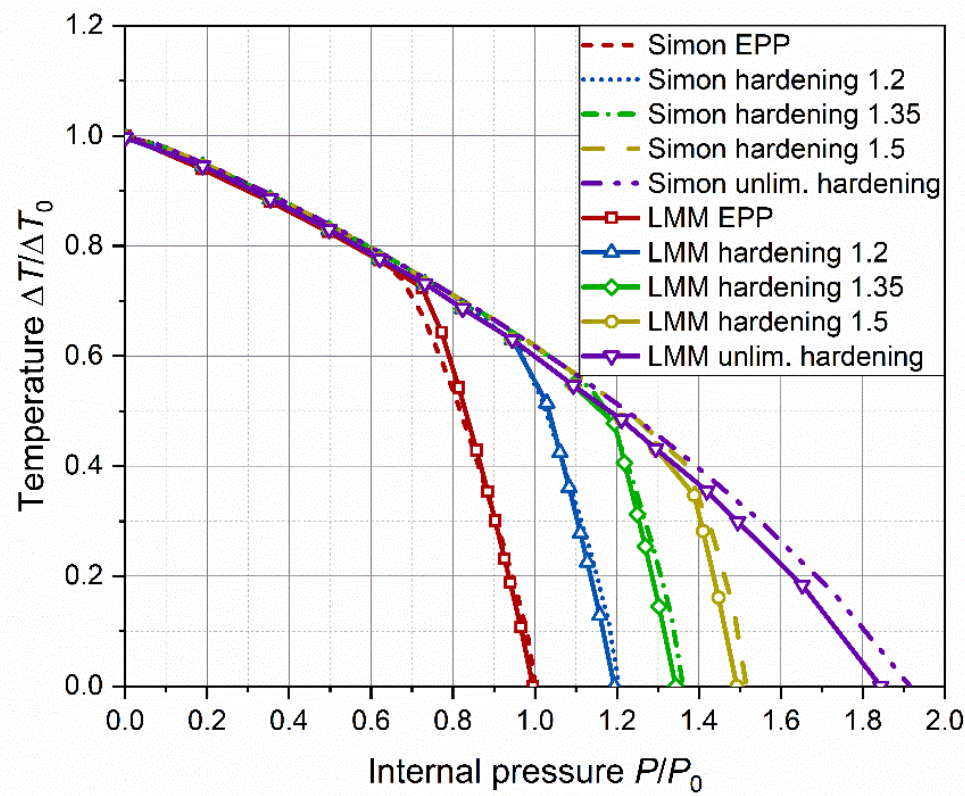

Fig. 8. Comparison of shakedown boundaries with results from (Simon, 2013). 


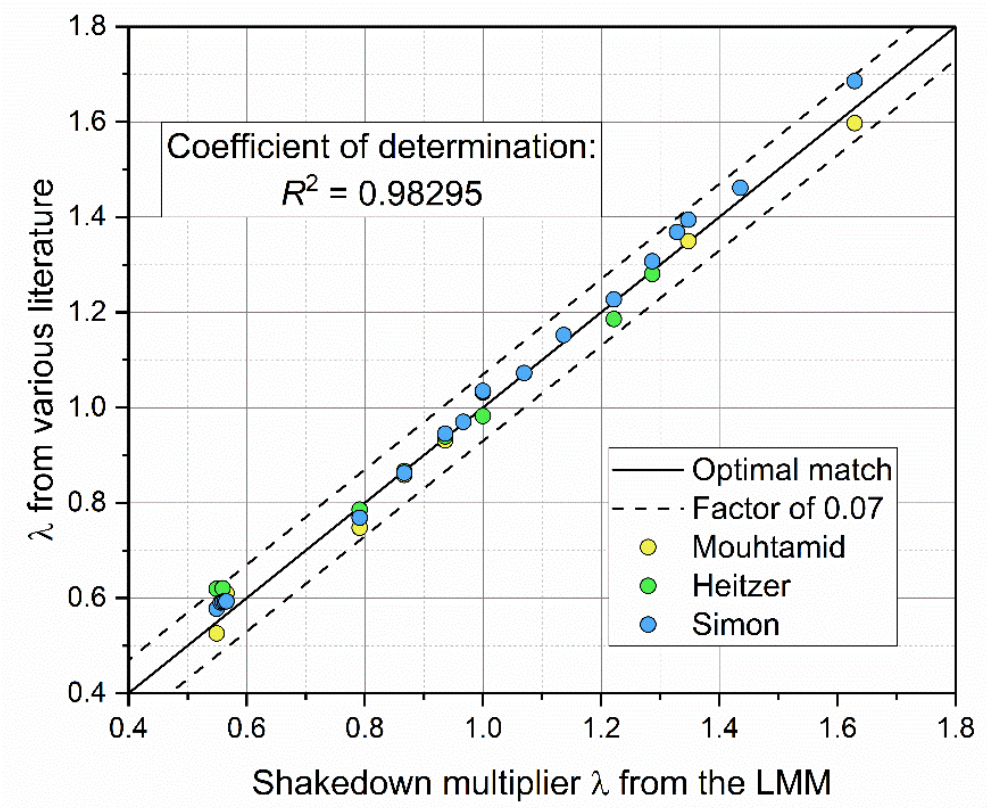

Fig. 9. Comparison of the shakedown multiplier $\lambda$ obtained with the LMM and literature.

\subsection{An aero-engine turbine disk}

As a critical component in the aerospace industry, the turbine system provides power for the engine and operates in a high-temperature working environment with high rotation speed, which imposes cyclic thermomechanical loads on the structure. The reliability of the turbine disk has a significant impact on the efficiency and longevity of the aero-engine (Jin, Hao, \& Huang, 2015). Thus it is essential to conduct the shakedown analysis to determine its shakedown limit considering the effect of kinematic hardening and temperature-dependent material properties for improved prediction accuracy.

Since the turbine disk is a body of revolution, it has been simplified to an axisymmetric model, as shown in Fig. 10. It should be mentioned that the mounting structures and small bores are neglected because they have been justified to have little influence on the shakedown analysis. The FE model is then meshed into 1975 quadratic elements of type CAX8R, as shown in Fig. 11. For a normal operating condition, the turbine disk is subjected to the centrifugal force $F$ caused by body rotation, the equivalent pressure $P_{e q}$ caused by the rotation of turbine blades, and the thermal stress caused by the temperature difference $\Delta \theta$. The working rotational speed $\omega$ and the mass of the turbine disk are also given in Fig. 11. For a typical operating condition, $\omega=1780.24 \mathrm{rad} / \mathrm{s}$ and $P_{e q}=148.835 \mathrm{MPa}$. All the mechanical loads are proportionally scaled by the developed subroutine until the structural shakedown limit is reached. Apart from the axisymmetric boundary condition, a displacement restriction is applied on the bottom edge to prevent axial movement.

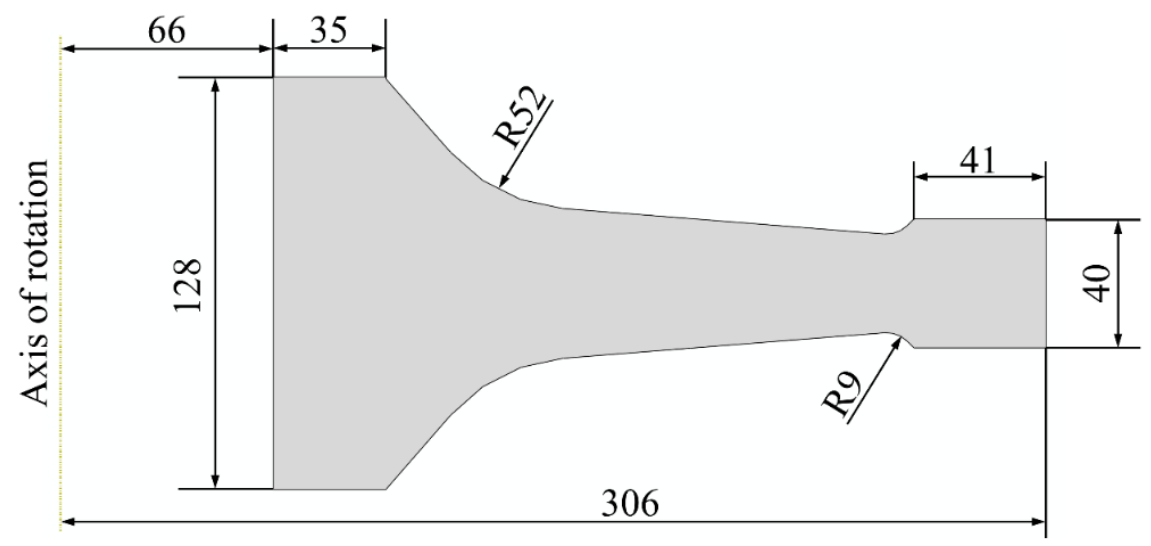

Fig. 10. The geometric sizes of a typical turbine disk. 


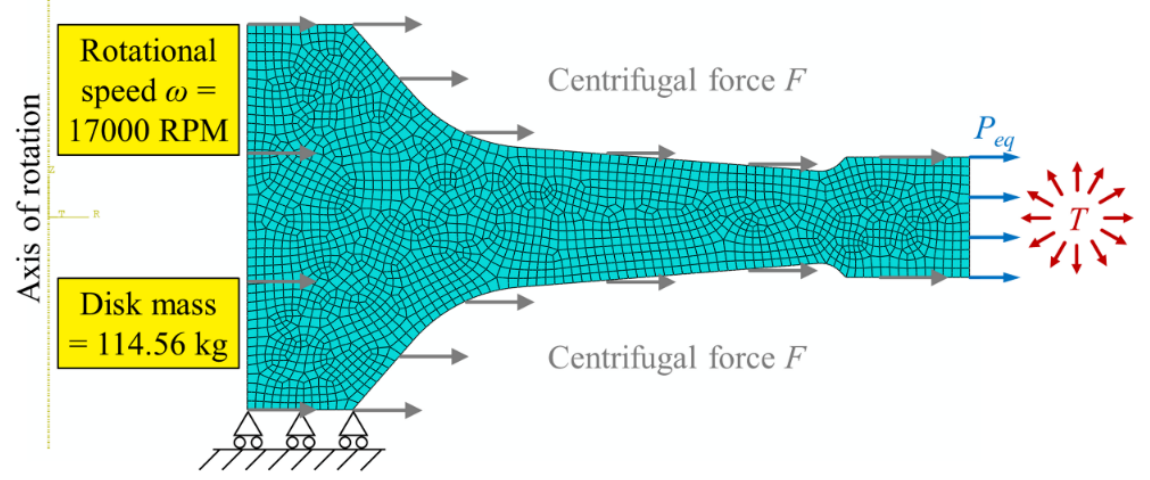

Fig. 11. The FE mesh and a typical operating condition.

A simplified loading condition has been generated based on the load spectrum of a typical flight, as given in Fig. 12. Some fluctuation during the loading and unloading process has been ignored due to the path-independency of the extended LMM algorithm. The dwell time between loading and unloading stages is also neglected because the creep effect is not considered in this case. Two different loading domains are considered here for the comparison study. Loading domain I contains 2 load instances: $V(1)=(0,0), V(2)=(M, \Delta \theta)$; loading domain II also contains 2 load instances: $V(2)=$ $(M, \Delta \theta), V(3)=(M, 0)$. Here $M$ represents mechanical loads and $\Delta \theta$ denotes temperature difference (thermal loads).

The material of the turbine disk is the nickel-based superalloy GH4169 featuring excellent hightemperature performance, formability and weldability. Hence it is widely used in the aerospace industry for high-temperature components. All the temperature-independent and the temperaturedependent material properties adopted for the analysis are given in Table 1 and Table 2, respectively. As mentioned in Section 3.1, instead a constant value, a dynamic ratio of bounding strength to yield strength $K(T)$ is considered based on the nodal temperature, where $K(T)=\mathrm{UTS}(T) / \sigma_{S}(T)$. Both the tensile and yield strength of GH4169 is taken from (Kong, Li, Jin, \& Geng, 2011).

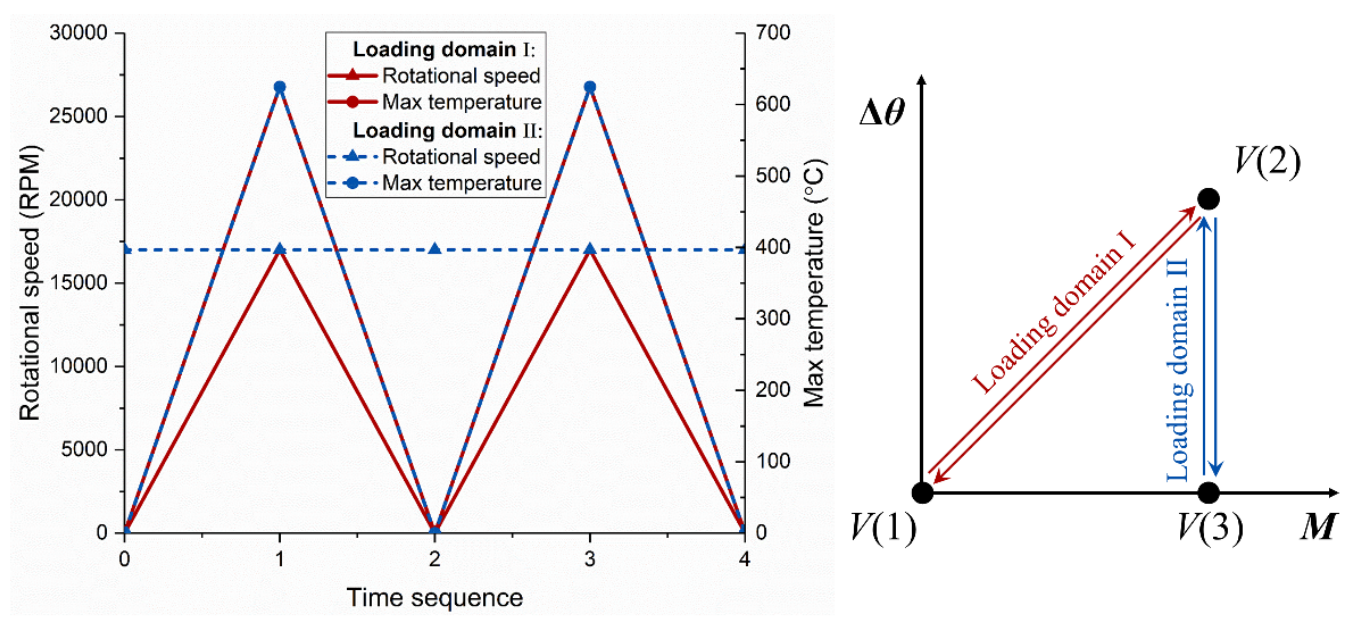

Fig. 12. A simplified load spectrum and the corresponding loading domains. 
Table 1 Temperature-independent material parameters of superalloy GH4169.

\begin{tabular}{ll}
\hline Conductivity, $k\left[\mathrm{~W} /\left(\mathrm{m} \cdot{ }^{\circ} \mathrm{C}\right)\right]$ & 23.6 \\
\hline Density, $\rho\left[\mathrm{g} / \mathrm{cm}^{3}\right]$ & 8.24 \\
\hline Young's modulus, $E[\mathrm{GPa}]$ & 177 \\
\hline Poisson's ratio, $v$ & 0.3 \\
\hline Thermal expansion coefficient, $\alpha\left[10^{-6} /{ }^{\circ} \mathrm{C}\right]$ & 17 \\
\hline Specific heat capacity, $c\left[\mathrm{~J} /\left(\mathrm{kg} \cdot{ }^{\circ} \mathrm{C}\right)\right]$ & 573.4 \\
\hline
\end{tabular}

Table 2 Temperature-dependent material parameters of superalloy GH4169.

\begin{tabular}{cccc}
\hline Temperature, $T\left({ }^{\circ} \mathrm{C}\right)$ & $\sigma_{S}(\mathrm{MPa})$ & $\mathrm{UTS}(\mathrm{MPa})$ & $K$ \\
\hline 0 & 1177 & 1377 & 1.170 \\
350 & 1156 & 1294 & 1.119 \\
450 & 1088 & 1196 & 1.099 \\
550 & 1117 & 1215 & 1.088 \\
600 & 1078 & 1215 & 1.127 \\
650 & 1000 & 1166 & 1.166 \\
700 & 951 & 1039 & 1.093 \\
750 & 764 & 862 & 1.128 \\
\hline
\end{tabular}

With the loading condition and material property provided, an elastic analysis can be performed to generate the data files for $\hat{\sigma}_{i j}$ in the shakedown analysis. It is worth mentioning that a steady-state thermal analysis is first conducted for normal operation state, as shown in Fig. 13(a). The temperature field is simplified and modified based on an industrial thermal analysis case of a comprehensive aeroengine turbine structure. The highest temperature is $624.1{ }^{\circ} \mathrm{C}$ at the edge of the turbine disk due to the conduction effect from the turbine blade, while the lowest temperature is $252.9^{\circ} \mathrm{C}$ at the part of the turbine disk connected to the rotation shaft. A temperature gradient along the turbine disk is simulated, which would cause significant thermal stress within the component. The thermal stress can then be calculated in ABAQUS based on the predefined temperature field, as presented in Fig. 13(b). The pure mechanical stress can also be computed considering the centrifugal force $F$ and the equivalent blade pressure $P_{e q}$, as shown in Fig. 13(c). It can be observed that the highest thermal stress appears at the end part of the turbine disk while the mechanical stress concentrates near the rotation axis. This suggests that the failure location and mechanism may be different for various load cases where thermal or mechanical loads dominant. Further discussion will be made later for better clarification. 


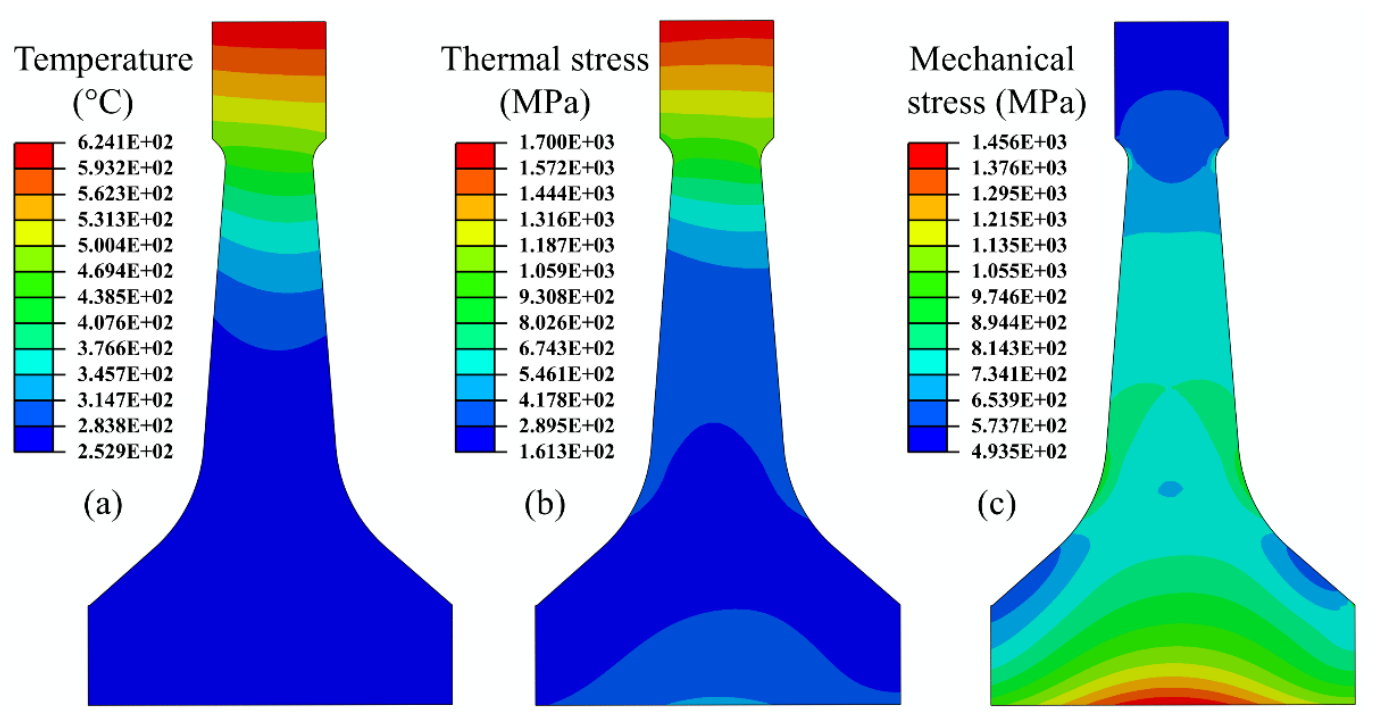

Fig. 13. Elastic analysis contours: (a) temperature field; (b) thermal von Mises stress; (c) mechanical von Mises stress.

The shakedown boundary considering kinematic hardening and temperature-dependent material properties with loading domain I has been evaluated and presented in Fig. 14. Both the mechanical load $M$ and the temperature difference (thermal load) $\Delta \theta$ are normalised by the reference loading condition as given in Fig. 12. It can be seen that the load case for normal operating loading condition $\left(M / M_{0}, \Delta \theta / \Delta \theta_{0}\right)=(1,1)$ is within the shakedown envelope, which means that the structure fully satisfies the shakedown criteria with the design operating condition. For abnormal working state and research purpose, it is of great importance to study other different loading combinations and the corresponding shakedown limit, which forms the data points and the shakedown boundary in Fig. 14. Unlike the ordinary shakedown boundary in Fig. 6 , the shakedown multiplier $\lambda$ increases first, and then decrease with a rising ratio of mechanical load to thermal load $\eta=M / \Delta \theta . \lambda$ reaches its maximum value at $\eta=0.8$. The reason is that thermal and mechanical load counteract with each other in the structure and the high-stress in some region is cancelled out with the presence of both thermal and mechanical stress.

As mentioned before, thermal and mechanical loads may induce distinct failure mechanisms that are also reflected in Fig. 14. A dashed black line of $\eta=0.8$ is drawn as a divide between two failure mechanisms: low-cycle fatigue and incremental collapse, for the EPP material. Low-cycle fatigue is a local failure mechanism caused by the dominant thermal load with $\eta<0.8$. Both the shakedown boundary for EPP material and the unlimited hardening boundary coincide with the alternating plasticity boundary, which is not affected by the limited kinematic hardening behaviour; while incremental collapse is a global failure mechanism caused by the dominant mechanical load with $\eta>$ 0.8. The unlimited hardening boundary is separated from the EPP shakedown boundary after the separation point $(1.12,1.40)$. The shakedown boundary considering limited kinematic hardening material is bounded by both the unlimited hardening limit and the ratchet limit, which is calculated with the temperature dependent UTS. For further illustration, two load cases have been selected near the separation point, and the corresponding contours of the effective plastic strain during the cycle are shown in Fig. 15. Load case (1) represents a data point $(0.96,1.38)$ and is thermal load dominant. The structural failure would commence at the outer edge of the turbine disk. While load case (2) represents a data point $(1.28,1.28)$ and is mechanical load dominant. In this case, the structure would fail at the location near the rotation shaft. 


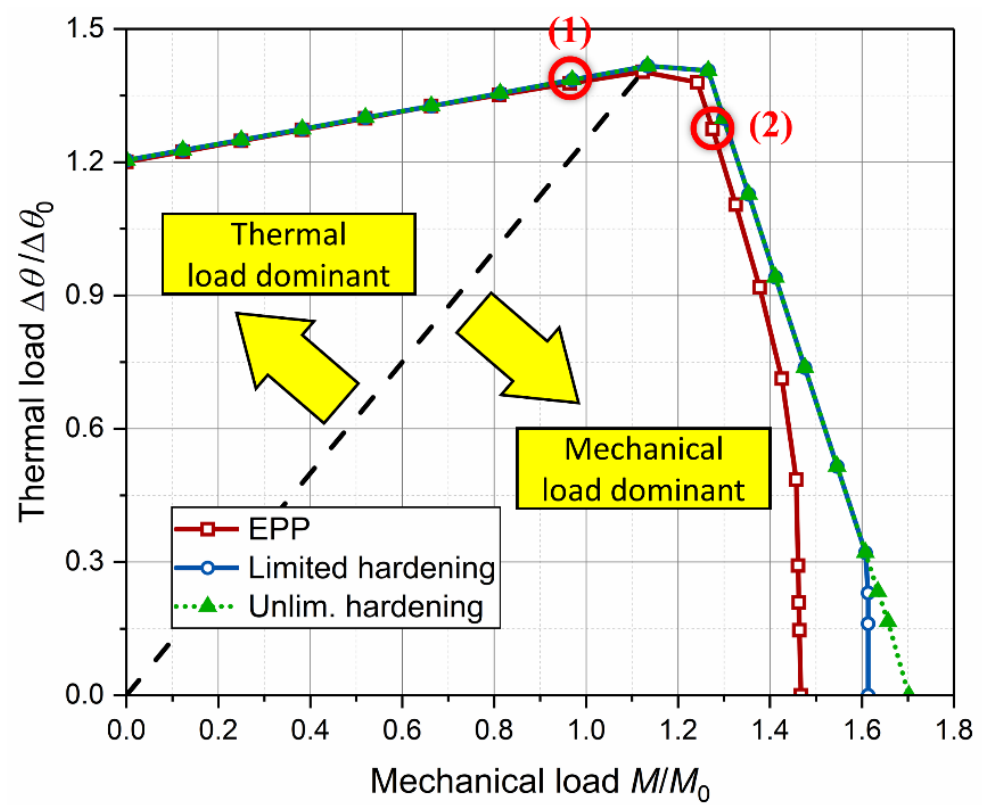

Fig. 14. Shakedown analysis considering kinematic hardening and temperature-dependent material properties with loading domain I.
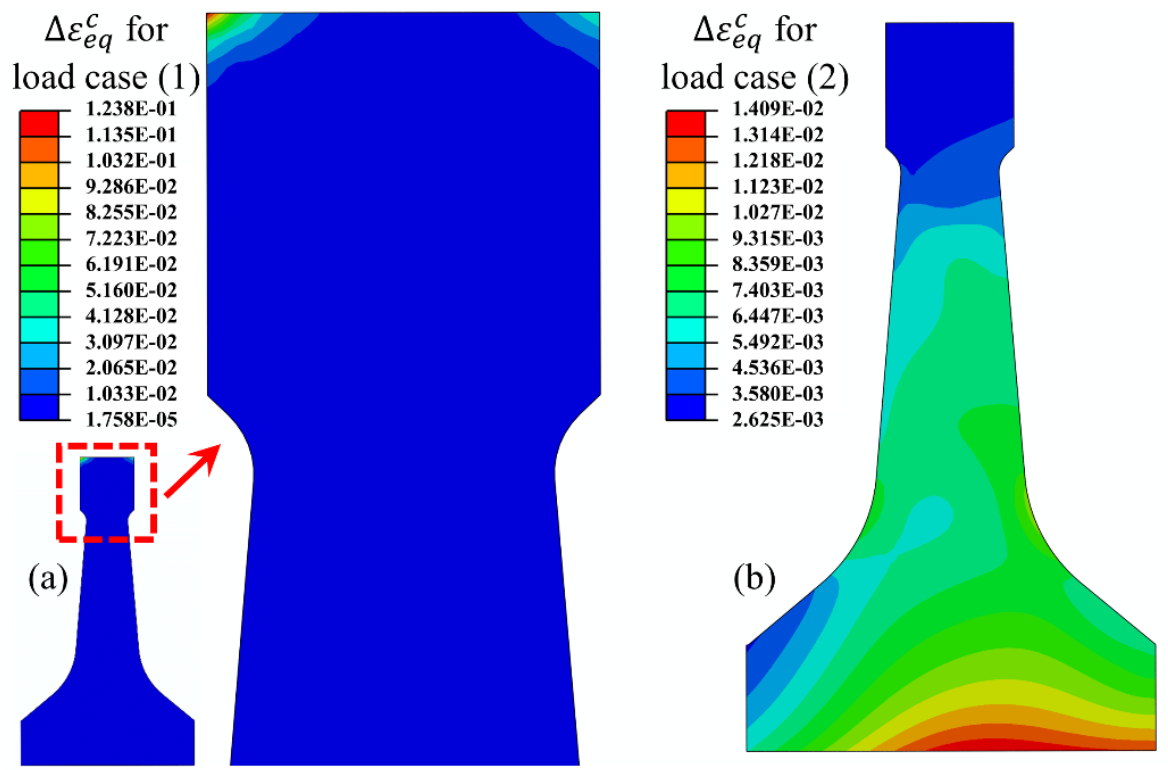

Fig. 15. The failure mechanism for two different load cases.

To study the influence of temperature-dependent material properties, a series of shakedown analyses using constant yield stress and UTS have been conducted for comparison, as shown in Fig. 16. The yield stress and UTS at $0{ }^{\circ} \mathrm{C}$ have been chosen from Table 2 as the temperature-independent material properties. It can be seen that the shakedown boundaries at the bottom with constant material properties are nearly identical to the ones with temperature-dependent properties because thermal load multiplier is relatively small while the nodal temperature is quite low. However, with the rise of temperature multiplier, the temperature-dependent material properties have an increasing influence on the results. A similar phenomenon has been observed and explained in (Haofeng Chen, 2010). Due to the counteracting effect of thermal and mechanical loads, the most significant difference between boundaries with temperature-dependent and constant material properties can be found near the transition point of failure mechanisms.

Meanwhile, the loading domain II with constant mechanical load and varying thermal load given in Fig. 12 is considered to simulate the fluctuation of heat flux while remaining steady rotation speed. As presented in Fig. 17, the loading domain II produces a horizontal part in the shakedown boundary. 
It is a common phenomenon for typical Bree-like diagram in (Bree, 1989) where the maximum value of the elastic thermal stress is twice the yield stress for the horizontal alternating plasticity limit. Similarly, as discussed in Fig. 16, the influence of temperature-dependent material properties grows with an increasing thermal load multiplier. Besides, it can be observed that temperature-dependent material properties have a more substantial effect on the shakedown boundary with limited hardening material compared to the one with EPP material when the temperature is low, which means that the shakedown limit for limited kinematic hardening material may be more sensitive to the temperaturedependence of material properties. Also, the shakedown limit with temperature-dependent material properties is always more conservative than the one with constant material properties. Therefore, it is vitally important to consider temperature-dependent material properties in the shakedown analysis along with the effect of kinematic hardening for the industrial requirement of conservatism and accuracy.

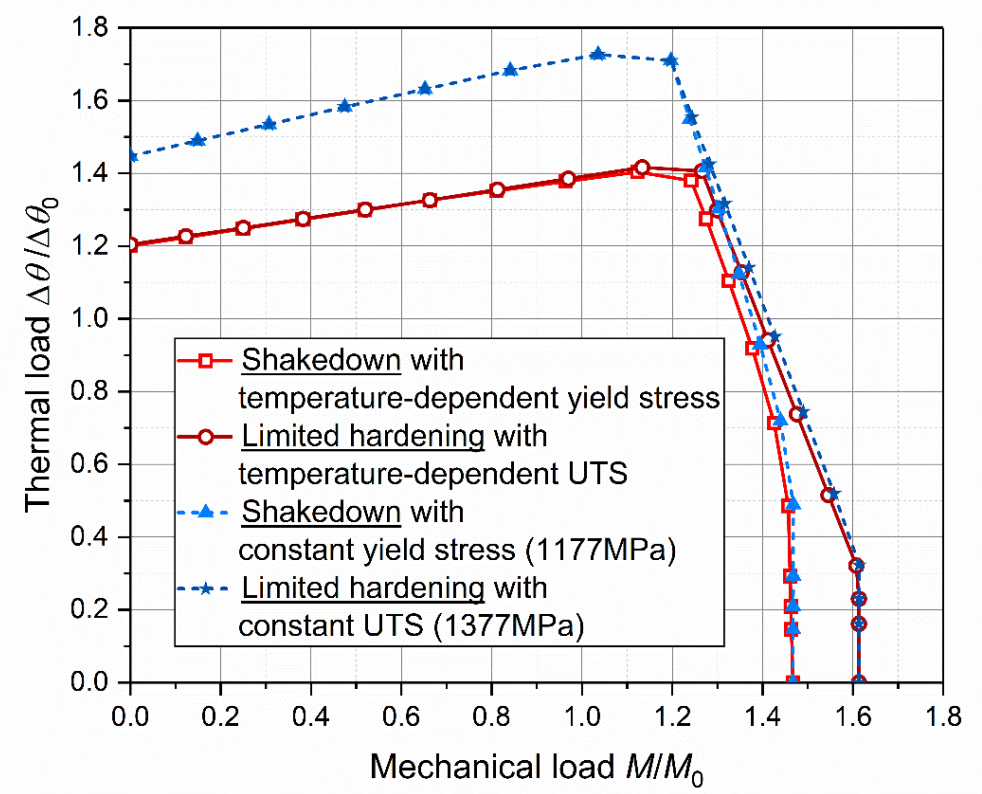

Fig. 16. Comparison of shakedown boundary considering temperature-dependent and constant material properties with loading domain I.

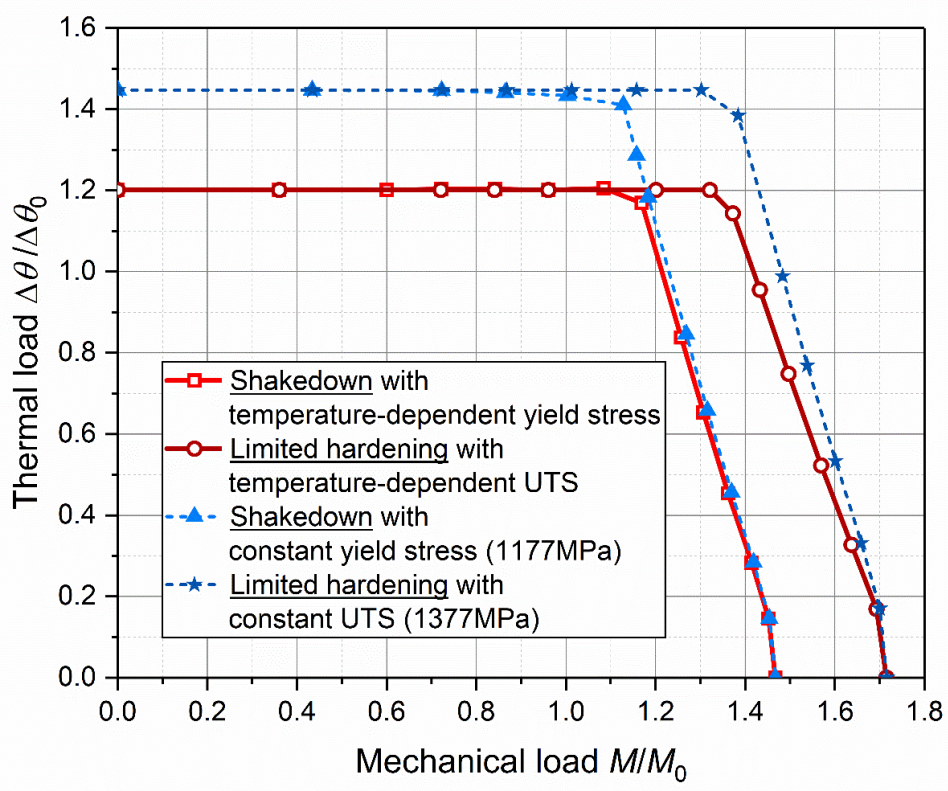

Fig. 17. Comparison of shakedown boundary considering temperature-dependent and constant material properties with loading domain II. 


\section{Conclusions}

The classical Melan's static shakedown theorem has been extended to consider limited kinematic hardening material using a two-surface hardening model. It has been further developed and implemented into the LMM shakedown module in this work. Also, for the first time, the temperature dependency of material properties has been adequately discussed and considered in the proposed extended LMM shakedown algorithm. To validate the reliability of the newly developed shakedown algorithm, a numerical test on a thin cylinder pipe has been done, and the shakedown curves with temperature-independent material properties have been derived. A series of fictitious hardening factor is assumed, and the corresponding results have been compared with the works of other researchers. Then, another numerical example of an aero-engine turbine disk with cyclic thermomechanical loads is given to show the capability of the proposed shakedown algorithm. The shakedown curve considering limited kinematic hardening and temperature-dependent material properties has been presented, and the failure mechanisms of load cases with thermal load dominance and mechanical load dominance have been observed and discussed. Finally, a number of conclusions can be drawn as follows:

1) For the numerical example of the thin cylinder pipe, the shakedown boundaries considering limited kinematic hardening and the unlimited hardening boundaries from the extended LMM all agree well with ones from literature by allowing an error factor of 0.07 , which builds the confidence in the accuracy of extended LMM method.

2) For the numerical example of the aero-engine turbine disk, load cases with the maximum counteract effect of thermal and mechanical loads would cause a transition point in the shakedown boundary. Different loading domains have an effect on the shape of the shakedown envelope, while temperature-dependent material properties influence the size of the shakedown envelope. Comparing to constant material properties, the results are more conservative when considering temperature-dependent material properties, especially when the temperature multiplier is high enough.

3) The extended Melan's static shakedown theorem considering limited kinematic hardening material and non-isothermal effect has been successfully implemented into the extended LMM shakedown module. The extended LMM shakedown algorithm has been proven to be robust, efficient and versatile for practical industrial problems.

\section{Acknowledgements}

The authors gratefully acknowledge the supports from Professor A.R.S Ponter of University of Leicester, the National Natural Science Foundation of China (51828501), the Higher Education Discipline Innovation Project (111 Project) under the funding code B13020, University of Strathclyde and East China University of Science and Technology during the course of this work. 


\section{References}

Ainsworth, R. A. (2003). R5: Assessment Procedure for the High Temperature Response of Structures: British Energy Generation Ltd.

Armstrong, P. J., \& Frederick, C. (1966). A mathematical representation of the multiaxial Bauschinger effect (Vol. 731). Berkeley: Central Electricity Generating Board [and] Berkeley Nuclear Laboratories, Research \& Development Department.

Boiler, A., \& Code, P. V. (2007). Section VIII, Division 2: Alternative rules, rules for construction of pressure vessels. New York: American Society of Mechanical Engineers.

Bouby, C., de Saxcé, G., \& Tritsch, J.-B. (2009). Shakedown analysis: comparison between models with the linear unlimited, linear limited and non-linear kinematic hardening. Mechanics Research Communications, 36(5), 556-562.

Bree, J. (1989). Plastic deformation of a closed tube due to interaction of pressure stresses and cyclic thermal stresses. International Journal of Mechanical Sciences, 31(11-12), 865-892.

Chen, H. (2010). Lower and upper bound shakedown analysis of structures with temperaturedependent yield stress. Journal of Pressure Vessel Technology, 132(1), 011202.

Chen, H., \& Ponter, A. R. (2001). Shakedown and limit analyses for 3-D structures using the linear matching method. International Journal of Pressure Vessels and Piping, 78(6), 443-451.

Chen, H., \& Ponter, A. R. (2010). A direct method on the evaluation of ratchet limit. Journal of Pressure Vessel Technology, 132(4), 041202.

Chen, S., Liu, Y., Li, J., \& Cen, Z. (2011). Performance of the MLPG method for static shakedown analysis for bounded kinematic hardening structures. European Journal of MechanicsA/Solids, 30(2), 183-194.

Hachemi, A. (2005). Sur les méthodes directes et leurs applications. (Habilitation), Université des Sciences et Technologies de Lille, France.

Heitzer, M., Pop, G., \& Staat, M. (2000). Basis reduction for the shakedown problem for bounded kinematic hardening material. Journal of Global Optimization, 17(1-4), 185-200.

Huang, S., Wan, F., Jiao, P., \& Chen, Z. (2018). A modified basis reduction method for limited kinematic hardening shakedown analysis under complex loads. Mechanics Based Design of Structures and Machines, 46(1), 85-100.

Jin, Y., Hao, Y.-h., \& Huang, Z.-j. (2015). Analysis of temperature field and stress field for the twinweb turbine disk of aero engine. Journal of Zhengzhou University of Light Industry (Natural Science Edition), 1, 019.

Koiter, W. T. (1960). General theorems for elastic plastic solids. Progress of Solid Mechanics, 167221.

Kong, X., Li, B., Jin, Z., \& Geng, W. (2011). Broaching performance of superalloy GH4169 based on FEM. Journal of Materials Science \& Technology, 27(12), 1178-1184.

König, J. A. (2012). Shakedown of elastic-plastic structures (Vol. 7): Elsevier.

Lytwyn, M., Chen, H., \& Ponter, A. R. (2015). A generalised method for ratchet analysis of structures undergoing arbitrary thermo - mechanical load histories. International Journal for Numerical Methods in Engineering, 104(2), 104-124.

Mackenzie, D., Boyle, J., \& Hamilton, R. (2000). The elastic compensation method for limit and shakedown analysis: a review. The Journal of Strain Analysis for Engineering Design, 35(3), 171-188.

Melan, E. (1938). Zur plastizität des räumlichen kontinuums. Archive of Applied Mechanics, 9(2), $116-126$.

Mouhtamid, S., \& Weichert, D. (2008). Anwendung direkter Methoden zur industriellen Berechnung von Grenzlasten mechanischer Komponenten. (Ph.D.), RWTH Aachen University, Germany.

Pham, D. C. (2007). Shakedown theory for elastic plastic kinematic hardening bodies. International Journal of Plasticity, 23(7), 1240-1259.

Pham, D. C. (2008). On shakedown theory for elastic-plastic materials and extensions. Journal of the Mechanics and Physics of Solids, 56(5), 1905-1915. 
Pham, D. C. (2017). Consistent limited kinematic hardening plasticity theory and path-independent shakedown theorems. International Journal of Mechanical Sciences, 130, 11-18.

Polizzotto, C. (1993). On the conditions to prevent plastic shakedown of structures: Part I-Theory. Journal of applied mechanics, 60(1), 15-19.

Ponter, A. (1975). A general shakedown theorem for elastic/plastic bodies with work hardening.

Ponter, A. R., \& Engelhardt, M. (2000). Shakedown limits for a general yield condition: implementation and application for a von Mises yield condition. European Journal of Mechanics-A/Solids, 19(3), 423-445.

Prager, W. (1955). The theory of plasticity: a survey of recent achievements. Proceedings of the Institution of Mechanical Engineers, 169(1), 41-57.

Pycko, S., \& Maier, G. (1995). Shakedown theorems for some classes of nonassociative hardening elastic-plastic material models. International Journal of Plasticity, 11(4), 367-395.

Ri, J.-H., \& Hong, H.-S. (2018). A basis reduction method using proper orthogonal decomposition for shakedown analysis of kinematic hardening material. Computational Mechanics, 1-13.

Seshadri, R. (1995). Inelastic evaluation of mechanical and structural components using the generalized local stress strain method of analysis. Nuclear Engineering and Design, 153(23), 287-303.

Simon, J.-W. (2013). Direct evaluation of the limit states of engineering structures exhibiting limited, nonlinear kinematical hardening. International Journal of Plasticity, 42, 141-167.

Stein, E., Zhang, G., \& Huang, Y. (1993). Modeling and computation of shakedown problems for nonlinear hardening materials. Computer Methods in Applied Mechanics and Engineering, 103(1-2), 247-272.

Svensson, N. (1966). Ageing and the Bauschinger Effect in Mild Steel. Nature, 211(5046), 290.

Weichert, D., \& Gross-Weege, J. (1988). The numerical assessment of elastic-plastic sheets under variable mechanical and thermal loads using a simplified two-surface yield condition. International Journal of Mechanical Sciences, 30(10), 757-767.

Ziegler, H. (1959). A modification of Prager's hardening rule. Quarterly of Applied mathematics, $17(1), 55-65$. 